This is the author's Post-print version (final draft post-refereeing as accepted for publication by the journal). The definitive, peer-reviewed and edited version of this article is published as: van Ham M. and Feijten P.M. (2008) Who wants to leave the neighbourhood? The effect of being different from the neighbourhood population on wishes to move. Environment and Planning A 40(5), 1151-1170. http://dx.doi.org/10.1068/a39179

\title{
Who wants to leave the neighbourhood? The effect of being different from the neighbourhood population on wishes to move
}

\author{
Maarten van Ham* and Peteke Feijten** \\ University of St Andrews, School of Geography \& Geosciences, Irvine Building, North \\ Street, St Andrews, Fife, KY16 9AL, UK. Phone +44 (0)1334 463912, Fax +44 (0)1334 \\ 463949, *E-mail: maarten.vanham@st-andrews.ac.uk, **peteke.feijten@st-andrews.ac.uk
}

\begin{abstract}
Little attention has been paid to date to the role of the neighbourhood as a factor influencing residential mobility and the residential choice process. The question addressed here is to what extent neighbourhood characteristics (percentage of rented dwellings, low income households and ethnic minorities in the neighbourhood) influence different categories residents wish to leave their neighbourhood. The answer to this question is capable of enhancing our understanding of residential mobility and mechanisms causing segregation by income and ethnic groups. We use data from the 2002 Netherlands Housing Demand Survey, enriched with neighbourhood characteristics. Whether or not people wish to leave their neighbourhood is estimated using a multilevel logistic regression model with cross-level interaction effects between individual and neighbourhood characteristics. The main result shows that with an increasing percentage of people from an ethnic minority in the neighbourhood, more people have the wish to leave the neighbourhood. However, this is to a lesser extent the case for members of ethnic minorities themselves.
\end{abstract}

Keywords: Residential mobility, moving wish, neighbourhood effects, segregation, population mix, tenure mix, multilevel model

\section{Introduction}

Literature aimed at enhancing our understanding of residential mobility and the residential choice process has emphasized the role of (changing) household characteristics and the characteristics of the dwelling. Much less attention has been paid to the role of the neighbourhood as a factor influencing residential choice. Although it is clear that most moves are triggered by the wish to make gains in the size and quality of the dwelling, moves may also be intended to improve neighbourhood quality (Meen \& Meen, 2003; Kearns \& Parkes, 2003). While substantial work has been carried out on the way neighbourhoods influence housing satisfaction (see Parkes et al., 2002), we do not as yet know much about how neighbourhoods influence residential mobility behaviour (Clark et al., 2006).

There are two bodies of literature which enhance our understanding of the effect of neighbourhoods on residential mobility, and which could also benefit from more knowledge about the underlying mechanisms. The first is the literature on neighbourhood effects: the 
effects of a deprived neighbourhood on the residents' social opportunities (see for a review Ellen \& Turner, 1997; Galster, 2002; Leventhal \& Brooks-Gunn, 2000; Sampson et al., 2002). A major problem in the neighbourhood effects literature is identification of causal relationships. Often, neighbourhood characteristics cannot be directly related to outcomes at the individual level because sorting into neighbourhoods is not based on a random process (Manski, 1993; Moffitt, 1998; Brock \& Durlauf, 2003; Durlauf, 2004). These selection mechanisms can be expected to cause biased (upward or downward) neighbourhood effects (Evans et al., 1992; Plotnick \& Hoffman, 1999). Surprisingly, the neighbourhood effect literature pays scant attention to selective residential mobility into and out of neighbourhoods, while more knowledge could enhance our understanding of the mechanisms behind neighbourhood effects.

The second relevant body of literature deals with segregation: the occurrence of high concentrations of poor households and/or ethnic minorities in some neighbourhoods. Most work on segregation investigates the changing patterns of population composition of neighbourhoods over time. Again, with a few exceptions, surprisingly little attention has been paid to the role of residential mobility, while selective residential mobility between neighbourhoods is at the heart of understanding segregation (Massey et al., 1994; South \& Crowder, 1997). Moreover, hardly any attention has been paid to the role of neighbourhood characteristics in shaping individual residential mobility decisions. An important exception is the body of research originating from Schelling's theoretical work $(1969,1971)$. Schelling's segregation hypothesis suggests that people do not want to be part of a minority population in their neighbourhood and that they are more likely to have a wish to leave their neighbourhood when they are different from their neighbours (see also Clark, 1991).

This paper is a contribution to a better understanding of the role of neighbourhood characteristics in individual residential moving behaviour in the Netherlands. We report the effects of several neighbourhood characteristics - which are often associated with deprived neighbourhoods - on people's wish to leave the neighbourhood. It was hypothesised that people living in concentration neighbourhoods (measured by a high percentage of lowincome households, rented homes or ethnic minorities) are more likely to have a wish to leave their neighbourhood. Following the Schelling-based literature, it was also hypothesised that, if the characteristics of the neighbourhood population and the individual match, people are less likely to have a moving wish compared with the situation when these sets of characteristics differ. People's own income, tenure, and ethnic background are therefore also taken into account.

\section{Theory and research context}

Most literature on residential moving behaviour deals with actual moves and not with people's wishes or intentions to move (some exceptions are Morris et al., 1976; Varady 1989; Kearns \& Parkes, 2003). We analyse people's wish to leave the neighbourhood rather than moving intentions or actual moving behaviour. If people have the wish to leave their neighbourhood this can be expected to be a direct response to deficits in the residential environment, without people taking their resources and restrictions into account. Intentions are much more linked to having the option to move and actual mobility behaviour only occurs when there are no constraints or restrictions preventing a wish from being realized (Lu, 1999). If we would look at moving intentions or actual moving behaviour, we would miss all those people who want to leave, but are unable to do so because of housing market constraints and the direct and indirect monetary and non-monetary costs involved in moving.

Because wishes often precede actual moves, factors known to influence residential mobility can also be expected to play a large part in explaining people's wish to move. 
However, not all wishes lead to actual moving behaviour and not all categories of people face the same restrictions, so the determinants of wishes to move and actual moves may differ (see $\mathrm{Lu}, 1999$ for an overview). Although this study aims to understand why people want to leave their neighbourhood, we briefly review some of the literature on residential mobility behaviour in general. It is very likely that there is substantial overlap between the factors which influence people's wish to leave the neighbourhood and factors influencing general moving wishes and behaviour.

The classic view of residential mobility is that people's decision to change residence is a function of dissatisfaction with the present housing situation, mainly caused by changes in the household (composition) that lead to the need for more (or less) space (Browne \& Moore, 1970; Speare et al., 1975). In his classic work on this topic, Rossi (1955) stressed that age and household composition are among the most important predictors of general residential mobility (see also Mulder, 1993; Feijten et al., 2003). Income (and indirectly level of education) is also thought to be an important factor in understanding the housing career and the neighbourhood career of households (Clark et al., 2006). Those with a higher income can be expected to be more satisfied with their housing situation and therefore less likely to consider a move. On the other hand, high income groups have more options to improve their housing situation and neighbourhood and might be more likely to have the wish to move (see $\mathrm{Lu}, 1999)$. With regard to ethnicity it can be argued that, after controlling for socioeconomic characteristics, ethnicity should not have an effect on people's wish to leave the neighbourhood. On the other hand, many studies show that, for a variety of reasons, people belonging to an ethnic minority have more difficulty matching their preferences and socioeconomic status with a home and neighbourhood (Bolt \& Van Kempen, 2003). The result is that ethnic minorities are overrepresented in low quality housing and deprived neighbourhoods and are therefore more likely to have the wish to leave their neighbourhood. The wish to leave the neighbourhood can also be expected to be influenced by the characteristics of the dwelling in which people live. Homeowners and those living in singlefamily dwellings are known to be the least likely to (have the wish to) move (Clark \& Dieleman, 1996; Helderman et al., 2004). Those who are dissatisfied with their dwelling or live in crowded accommodation are more likely to consider a move (Landsdale \& Guest, 1985; Clark \& Dieleman, 1996).

\section{Wish to leave the neighbourhood}

Not only the dwelling, but also the neighbourhood can be a source of dissatisfaction, and can contribute to the wish to leave the neighbourhood. Two dimensions of the residential environment which can be expected to influence neighbourhood (dis)satisfaction can be distinguished: the physical structure of the neighbourhood and the neighbourhood population, representing the social dimension (Amérigo, 2002). An important characteristic of the physical dimension is building density, which is a good proxy for such factors as (noise) pollution, green public space, infrastructure, and the appearance of the built environment. Evidence from USA consistently shows that Americans prefer to live in low-density environments. Only a small part of the USA population has a strong preference for living in the highly-urbanized core areas of large cities (Brower, 1996; Talen, 2001). Similar evidence is available for Europe (Bootsma, 1998; Brun \& Fagnani, 1994; McDowell, 1997). Because in general people prefer low population densities, it was hypothesised that more people wish to leave the neighbourhood with increasing building density.

In Europe, there is currently a renewed interest in assessing levels of dissatisfaction with neighbourhoods, in particular with respect to the social dimension. Parkes and colleagues (2002) have shown that, in Britain, residential dissatisfaction is notably higher among the residents of poor neighbourhoods, but no effect of living in a poor area on moving 
intentions was found (Kearns \& Parkes, 2003). They did find an effect of discontent with the neighbourhood population. Unfortunately, their analyses did not reveal which aspects of the neighbourhood population cause people to wish to move house.

In this study, we focus on three neighbourhood characteristics relating to the neighbourhood population: the share of low incomes; the share of ethnic minorities; and the share of tenants (or rented dwellings). Neighbourhoods with concentrations of low incomes, rented housing, and ethnic minorities are often deprived or distressed neighbourhoods, places from which people want to escape. Of course, care is needed in denoting all these concentration neighbourhoods as undesirable neighbourhoods in which to live. More qualitative research designs are necessary to gain insight into the specific mechanisms at play in specific concentration neighbourhoods. The purpose of this study, however, is to look for general effects of the three neighbourhood characteristics on residents' wish to leave the neighbourhood and to test our hypotheses for a large variety of neighbourhoods so that low and high concentration neighbourhoods can be compared.

In general, people can be expected to want to escape from poor neighbourhoods, often referred to as 'pockets of poverty'. Considerable attention has been paid to poverty neighbourhoods in the social mobility literature. Wilson (1987) reopened the debate about the (negative) contextual effects of poor neighbourhoods on residents' social position and social opportunities. The conclusions of the research that followed were that there were indeed neighbourhood effects on such outcomes as school dropout rates (Overman, 2002); childhood achievement (Duncan et al., 1994); transition rates from welfare to work (Van der Klaauw \& Ours, 2003); deviant behaviour (Friedrichs \& Blasius, 2003); social exclusion (Buck, 2001); social mobility (Musterd et al., 2003). If poor neighbourhoods do indeed have these negative effects on people, those living there are highly likely to want move out of them. We therefore formulated the hypothesis that people are more likely to have the wish to leave their neighbourhood with increasing percentage of low income households in the neighbourhood (hypothesis 1a).

In the Netherlands, neighbourhoods with high concentrations of ethnic minorities are generally perceived as less desirable. Although levels of ethnic segregation and concentration are kept to a relatively low level by an impressive set of welfare state arrangements (Bolt et al., 2002), there are still relatively large differences between neighbourhoods. In some urban neighbourhoods, around 85 percent of the population consists of ethnic minorities. One of the reasons why people might want to leave these concentration neighbourhoods is discrimination towards some ethnic minority groups (see Bolt \& Van Kempen, 2003). Another reason might be that people simply prefer to live among people with the same ethnic background, partly because of the positive benefits that may arise from living in an ethnic cluster (Clark, 1992). One has to be aware of the fact that a high concentration of ethnic minorities in a neighbourhood often reflects poor housing conditions and a poor residential climate. Ethnic minorities concentrate in these neighbourhoods because they have fewer opportunities to escape (Bolt \& Van Kempen, 2003). One should therefore always control for satisfaction with the dwelling when considering the effect of living in a concentration area. Summarizing, we hypothesised that people are more likely to have the wish to leave their neighbourhood with increasing percentage of residents from ethnic minorities in the neighbourhood (hypothesis 1b; see also Crowder, 2000).

A large share of rented dwellings in the neighbourhood can also be expected to influence people's wish to move to another neighbourhood. In general, renters are thought to take less care of their dwellings and their residential environment, so that neighbourhoods with a lot of renters are less desirable places in which to live. Coulson and colleagues (2003) suggest that people are willing to pay more to live in neighbourhoods accommodating homeowners rather than renters. Higher rates of homeownership in neighbourhoods were 
found to be accompanied by higher housing prices, even after controlling for several neighbourhood characteristics, including ethnicity. These results indicate that neighbourhoods with a low percentage of homeowners - or a high percentage of rented homes - are considered less desirable neighbourhoods (Clark et al., 2006). We therefore expected that people are more likely to have the wish to leave the neighbourhood with increasing percentage of renters in the neighbourhood (hypothesis 1c).

In the above framework, the hypotheses on the effect of the neighbourhood population on moving wishes have mainly been derived from the idea that people have preferences with regard to the neighbourhood population mix. In two pioneering papers, Schelling $(1969,1971)$ suggests that a person's moving behaviour depends not only on the characteristics of the neighbourhood population, but also on the interaction between that person's own characteristics and the characteristics of the neighbourhood population. Schelling used this idea to explain segregation theoretically. Schelling postulated that unorganized individual behaviour with slightly different preferences towards white and black neighbours can lead to highly structured aggregate results (see also Clark, 1991). Individual preferences related to the ethnic composition of the neighbourhood population and the consequent moving behaviour of these individuals can cumulate in aggregate to highly segregated neighbourhoods. Clark's empirical examination of the Schelling hypothesis for the USA (1991) confirmed that the thesis is broadly correct, but that the differences in neighbourhood preferences between blacks and whites are significantly greater than those postulated by Schelling (see also other studies such as Clark, 1992; Ihlanfeldt \& Scafidi, 2002; Ioannides \& Zabel, 2003).

Schelling's central idea that one's residential behaviour can be influenced by one's own characteristics in combination with the characteristics of one's neighbours, or in more general terms, the neighbourhood population, is very important. Schelling's theoretical work and related empirical tests undertaken by others, mainly in USA, suggest that people do not want to be part of a minority population in their neighbourhood. On the basis of Schelling's work, it was hypothesised that a match between people's own characteristics and the characteristics of the neighbourhood population makes them less likely to have the wish to leave the neighbourhood (hypothesis 2).

\section{Data}

To test our hypotheses, we needed data at both individual and neighbourhood levels. The individual-level data used were taken from the 2002 Housing Demand Survey (WBO) of the Ministry of Housing, Spatial Planning and the Environment (VROM), which is available through the Netherlands Scientific Statistical Agency. The research population was representative of the Netherlands' population aged 18 and over and not living in an institution. The number of respondents was 75,043. The dataset includes detailed information on individual and household characteristics, including the present 4 -digit postal code. For the analysis, respondents between the ages of 18 and 80 were selected, excluding people living in shared housing such as student accommodation, and people living in non-house accommodation such as boats or trailers. Following this selection, the research sample consisted of 62,144 respondents.

We used four neighbourhood-level variables from the $\mathrm{ABF}$ Combimonitor: the percentage of rented houses in 2002 (original source ABF Research - SysWov); the percentage of non-western migrants in 2002 (original source CBS - Population statistics); the percentage of households in the lowest income quintile in 2002 (original source CBS Regional Income Survey); and the degree of urbanization of the postal code (original source CBS - Postcode Register). We have used data at the level of 4-digit postal codes because this 
is the lowest spatial level at which we can link neighbourhood data to individual respondents of the Housing Demand Survey. We are aware of the fact that there is no one-to-one relationship between 4-digit postal code areas and neighbourhoods as perceived by residents (see Galster, 2001). However, in urban areas 4-digit postal code come close to what people may perceive as their neighbourhood. Because of the high population density, urban postal codes are relatively small in size (one square kilometre or less). On average, the 4,000 Netherlands postal codes cover an area of 10 square kilometres and accommodate a population of 4,000 inhabitants.

For the whole of the Netherlands, about 8 percent of the postal codes can be classified as 'very strongly urbanized' and these urban postal codes house almost 18 percent of the Netherlands population. Almost 10 percent of the Netherlands population belongs to the category 'non-western ethnic minorities'. On the level of postal codes large differences exist with postcodes ranging from 0 to 85 percent ethnic minorities. Just over 20 percent of all postal codes have a more than average share of ethnic minorities and only one percent of all postal codes has more than 50 percent non-western ethnic minorities. In the Netherlands, 46 percent of all households live in rented accommodation. On the level of postal codes homeowners and renters are segregated with postal codes ranging from 0 to 100 percent rented dwellings. 25 Percent of the postal codes have an above average percentage of rented dwellings. With regard to income, 32 percent of the postal codes have an above average percentage of households in the lowest income quintile.

Table 1 presents the summary statistics and definitions of the variables used. For the dependent variable we used a direct measure of people's wish to leave the neighbourhood, based on the survey question: 'if possible, would you like to leave the neighbourhood?' The resulting dependent variable is dichotomous and indicates whether (1) or not (0) respondents have the wish to leave their neighbourhood. In total 18.7 percent of the respondents in the dataset have the wish leave their neighbourhood. Note that 55 percent of those with a wish to leave the neighbourhood do not have intentions to do so within the next two years. Several groups of independent variables are included in the analysis. The first group consists of individual and household characteristics. The second group of variables included in the analysis are characteristics of the dwelling. The third group of variables included in the analysis are neighbourhood characteristics.

---- please insert Table 1 about here ----

\section{Methodology}

Since the dependent variable is binary, a logistic regression model was used. Because the data contains more than one respondent per postcode, a simple logistic regression model would violate the standard assumption of the independence of observations. This clustering of data is handled by using a multilevel model. The model used has two levels: the postcode level, denoted by subscript $j$; the individual level, denoted by subscript $i$. The model allows for the inclusion of interactions between individual characteristics and neighbourhood characteristics (cross-level interactions). In the model, the intercept is assumed to vary randomly across individuals and neighbourhoods, but the relationship between the dependent and the independent variables is assumed to be the same for all individuals within a neighbourhood. This type of model is known as a random effects model or random intercept model (Snijders \& Bosker, 1999). It was decided to use a random effects model instead of a fixed effects model, because we wish to test effects of neighbourhood-level variables. Using a fixed effects model would already 'explain' all differences between neighbourhoods by the fixed effects and there would be no unexplained between-neighbourhood variability left that could be explained by the neighbourhood variables (Snijder \& Bosker, 1999). 
The intercept in the model consists of two terms: a fixed component $\beta_{0}$ and a neighbourhood-specific component, the random effect $u_{0 j}$. We assume that both the $u_{0 j}$ and $e_{i j}$ follow a normal distribution with mean zero and variance $\sigma_{\mathrm{u} 0}^{2}$ and $\sigma_{\mathrm{e}}^{2}$ respectively; they form the random part of the model (Rasbash et al., 2004). We also assume that, since they are at different levels, these variables are uncorrelated. The estimation was carried out using the software package MlwiN (Rasbash et al., 2004).

The basic form of our model is as follows:

$f\left(\pi_{i j}\right)=\beta_{0}+\beta_{1} x_{i j}+\beta_{2} z_{j}+\beta_{3} x_{i j} z_{j}+e_{i j}+u_{0 j}$

where...

$\pi_{i j} \quad$ represents the proportion of the sample scoring 1 on the binary response variable, in which score 1 stands for respondent $i$ in neighbourhood $j$ having the wish to leave the neighbourhood;

$\beta_{0} \quad$ is a constant (fixed intercept);

$\beta_{1} x_{i j}$ is the effect of an individual level characteristic of respondent $i$ (concerning the person, his/her household or his/her dwelling);

$\beta_{2} z_{j} \quad$ is the effect of a neighbourhood-level characteristic of neighbourhood $j$;

$\beta_{3} x_{i j} z_{j}$ is the effect of a cross-level interaction term between an individual characteristic of respondent $i$ and a neighbourhood-level characteristic of neighbourhood $j$;

$e_{i j} \quad$ is the individual-level random variation;

$u_{0 j} \quad$ is the neighbourhood-level random variation.

The three neighbourhood characteristics were included in the model as continuous variables. In the neighbourhood literature, it is often argued that effects are not linear, but that there are certain thresholds (or tipping points) below which there are no neighbourhood effects (see for example Clark, 1991; Durlauf, 2004). Tests using an alternative specification of our model using sets of dummies for categories of the neighbourhood characteristics showed linear effects comparable to the models including continuous variables. In order to specify the model as parsimonious as possible, we therefore used the continuous variables.

To assess the fit of our models, we performed a Wald test and we used Deviance Information Criterion (DIC) diagnostics. The DIC is derived by estimating the models using an MCMC estimation procedure in MlwiN (see Browne, 2004). The DIC can be used to compare models as it consists of the sum of two terms that measure the fit and the complexity of a model. Any decrease in DIC signifies model improvement, because the DIC is already corrected for the number of variables in a model (see also Spiegelhalter et al., 2002). Besides the outcomes of the multivariate models, we will also present some additional simulation results on predicted outcomes of the models. These simulations help to assess the total effect of the neighbourhood characteristics and the interaction effects with the individual characteristics on people's wish to leave the neighbourhood.

As referred to in the introduction, a key problem in the empirical investigation of neighbourhood effects is (econometric) identification of causal relationships (Manski, 1993; Moffitt, 1998; Brock \& Durlauf, 2003; Durlauf, 2004). Building on Manski (1993), Moffitt (1998) distinguishes three general problems: the simultaneity problem; the omitted-contextvariables problem; and the endogenous membership problem. The most acute is the simultaneity problem, or also referred to as Manski's (1993) reflection problem, which arises when a researcher tries to infer whether the average behaviour in some group influences the behaviour of the individuals that comprise the group. Problems with simultaneous causation may arise because the contextual conditions themselves may be caused by respondent's 
behaviour (endogenous effect). In our study we do not address the issue if someone's wish to leave the neighbourhood depends on whether others are likely to (have the wish to) move as well (endogenous effect). Our study is only on contextual effects of the presence of groups in the neighbourhood, so the reflection problem does not arise.

The second is the omitted-context variables problem, also called the correlated unobservables problem. This problem arises if important characteristics of the context are omitted from the regression and these unobserved variables (at neighbourhood level) are correlated with included variables. In our model we included four neighbourhood characteristics which we believe together form a meaningful summary of neighbourhood conditions. Of course there may be other neighbourhood characteristics which we do not observe and which may be correlated with included variables. However, we have to assume that the unobserved neighbourhood effects are random rather than fixed because at present little is known about how to handle fixed effects in cross-sections. A recent exception is a paper by Brock and Durlauf (2004) on the identification of binary choice models. They propose partial identification solutions, but these solutions have not yet matured.

The third problem is the endogenous membership problem. Also this problem involves omitted variables, but this time at the level of the individual. The core of this problem is self-selection into neighbourhoods. When sorting into neighbourhoods is not based on a random process and unobserved individual characteristics are correlated with the location decision and the dependent variable, this generates endogeneity. Also in our study it is likely that in the past people sorted into neighbourhoods based on individual preferences. Therefore, it is likely that at least a part of the people who prefer not to live in concentration neighbourhoods have sorted into other types of neighbourhoods. This selective sorting will probably cause our model to underestimate the effect of neighbourhood characteristics on the wish to leave because those most likely to be affected by these neighbourhood characteristics have not moved into these neighbourhoods in the first place. It is possible that the sorting mechanism is already explained by the variables included in our model, but ideally we would need extra information which enables us to model the sorting process itself. Unfortunately this information is not available in the data used. An alternative solution is to use an instrumental variable approach (IV) to overcome self-selection. This approach offers great potential for future work, but requires the data to include the necessary variables (Durlauf, 2004; Galster, 2003). We considered several instruments which had to be highly correlated with the dimensions of the neighbourhood in our model, but uncorrelated with unmeasured respondents characteristics and the wish to leave the neighbourhood. Finding such instruments proved to be impossible given the complex relationship between housing market behaviour and neighbourhood characteristics. Because we are not able to formally model the selection mechanism, in the conclusion we will pay ample attention to the potential effect selection might have on the outcomes of our study.

\section{Analysis}

Table 2 shows the results of a series of 5 multilevel logistic regression models estimating people's wish to leave the neighbourhood. An extra group of variables is added in each consecutive model. The first model (Model 0) is an intercept-only model and includes no explanatory variables. Model 1 includes a set of individual and household variables; Model 2 includes dwelling characteristics; Model 3 includes neighbourhood characteristics; Model 4 includes cross-level interaction terms; Model 5 includes extra variables on the neighbourhood

ethnic composition. At the bottom of the Table, chi square and DIC diagnostics are given for each model, showing that each additional set of variables improves the model fit. 
Model 0 only includes a constant and allows to decompose the total variance into the individual and the neighbourhood level by calculating the intra-class correlation coefficient. This coefficient is calculated from the random variance at the neighbourhood level $(0.266)$ and the variance of a logistic distribution with scale factor 1 (3.29) (see Rasbash et al., 2004). The intra-class correlation coefficient $(0.266 /[0.266+3.29])$ indicates that around 7.5 percent of the variation in moving wishes between respondents can be attributed to factors measured at the neighbourhood level. This percentage is relatively high and indicates that, potentially, some of the variation in moving wishes can be explained by neighbourhood characteristics. In Model 1, a set of personal and household characteristics are added to the model. The variance at the neighbourhood level decreased from 0.266 to 0.158 , indicating that the difference in moving wishes between neighbourhoods is half explained by composition effects of the population.

The effect of age on moving wishes is negative and the effect of age-squared is positive, indicating that, as expected, people are less likely to consider leaving the neighbourhood with increasing age, but as people become very old they are slightly more likely to have the wish to leave their neighbourhood. In contrast with one-person households, couples are less likely to have the wish to leave their neighbourhood, especially when they have children. One-parent households are slightly more likely than singles to have a moving wish. A possible cause may be a mismatch between the actual housing situation and the desired housing situation of one-parent households. With increasing income, people are less likely to have a moving wish. With regard to level of education, people with a medium educational level are the least likely to have a moving wish. People belonging to non-western ethnic minorities are significantly more likely to have a moving wish than others. The effects of income, level of education and ethnicity are likely to be caused by differences in housing and neighbourhood quality between groups and are therefore are expected to change once dwelling characteristics and housing satisfaction are controlled for (Model 2).

In Model 2, dwelling characteristics have been included, causing a further decrease of the variance at the neighbourhood level from 0.158 to 0.099 . This indicates that a substantial part of the difference in moving wishes between neighbourhoods can be explained by the variation in housing characteristics between neighbourhoods when socio-demographic characteristics of individuals are taken into account. The model shows that renters are more likely to have a wish to leave the neighbourhood than homeowners. The effect of living in a single-family dwelling is large and negative. When a household lives in a dwelling where at least one room per household member is available, it is less likely that they want to leave the neighbourhood than when less than one room per household member is available. Finally, housing satisfaction has a very strong effect on moving wishes. People who are satisfied with their housing situation are far less likely to have a wish to leave than people who are neutral or dissatisfied. Housing satisfaction roughly represents unmeasured housing characteristics that affect moving wishes. The results show that the wish to leave the neighbourhood cannot be seen apart from dwelling characteristics.

As expected, after adding dwelling characteristics to the model, the effects of income, level of education, and ethnicity changed. With increasing income, people are more likely to have the wish to move to further improve their housing situation and neighbourhood. With increasing level of education, people are also more likely to have a moving wish. The effect of ethnicity changed from positive to negative after controlling for characteristics of the dwelling, reflecting the poorer position of ethnic minorities on the housing market. The effect of household composition also changed after adding dwelling characteristics to the model. Couples without children are now more likely to have a moving wish than are singles or couples with children. 
In Model 3, the three main neighbourhood characteristics and degree of urbanization are added to the model to test the hypothesis that people living in concentration neighbourhoods are more likely to have a wish to leave the neighbourhood. By adding extra variables, the variance at the neighbourhood level again decreases: this time, from 0.099 to 0.074. This modest decrease indicates that the contribution of these neighbourhood characteristics to the explanation of variation in moving wishes is limited.

The set of dummies indicating the degree of urbanization of neighbourhoods show that people in more urbanized neighbourhoods are more likely to have a moving wish. As expected from the literature, a high building density is regarded as a negative characteristic. Neighbourhoods in the highest category of urbanization form an exception: people living here are no more likely to have a wish to move than people in areas that are not urbanized. This finding might be caused by the fact that these very strongly urbanized neighbourhoods are mainly located in the attractive centres of larger cities with amenities that compensate for the negative effects of a high building density.

The coefficient of percentage of ethnic minorities in the neighbourhood shows that with an increasing share of ethnic minorities in the neighbourhood, people are more likely to have a wish to leave the neighbourhood. Neither the effect of the percentage of low income households in the neighbourhood nor the effect of the percentage of rented dwellings in the neighbourhood is significant. Apparently, living in a poor neighbourhood or living in a neighbourhood with many rented dwellings has no effect on moving wishes after controlling for dwelling type and housing satisfaction of individuals; this conflicts with our hypotheses.

In Model 4, the hypothesis is tested that the more people resemble the neighbourhood population, the less likely they want to leave their neighbourhood. This testing was implemented by including cross-level interactions between individual and neighbourhood characteristics in the model. Three variables were constructed: interaction between having a low income and percentage of low-income households in the neighbourhood; interaction between belonging to an ethnic minority and percentage of ethnic minorities in the neighbourhood; interaction between being a renter and percentage of rented dwellings in the neighbourhood. The neighbourhood level variation decreased from 0.074 to 0.067 . That decrease is not very much, but the addition of interaction effects rarely has large effects on unexplained variation, because interaction effects do not add any new information to the model, but merely refine the main effects already present.

The results show that all three interaction effects are significant and in the expected direction. Having a low income, belonging to an ethnic minority or being a renter and living in a concentration neighbourhood (consisting of people's own category of people) decreases the probability that people have a wish to leave their neighbourhood. After adding the interaction effects, the main effect of percentage of renters in the neighbourhood is now positive and just significant, indicating that there is a small general effect of rented dwellings in the neighbourhood on the probability to have a moving wish. The main effect of the percentage of ethnic minorities in the neighbourhood has remained significantly positive and has even become a bit stronger.

The interaction effect between belonging to an ethnic minority and the percentage of ethnic minorities in the neighbourhood is interesting because it changed the main effect of people's own ethnic background. While in general concentrations of ethnic minorities increase the probability that people have a wish to leave their neighbourhood (main effect 0.022 , significant), it seems that the likelihood that those belonging to ethnic minorities themselves consider a move decreases when more people from ethnic minorities live in the neighbourhood (interaction effect -0.014 , significant). The finding that the main effect of individual ethnicity is no longer significant indicates that there is no independent effect of belonging to an ethnic minority on the wish to leave the neighbourhood, but that the ethnicity 
effect is composed of the on average poorer housing situation of ethnic minorities, their overrepresentation in high density neighbourhoods, and their general 'preference' to live among others of their own group.

The findings of Model 4 support the hypothesis derived from Schelling's work (1969, 1971). The desire to move out of one's neighbourhood seems to be shaped to some extent by one's attitude towards one's neighbours, since those people who belong to a minority are more likely to wish to leave the neighbourhood than those belonging to the majority. This finding seems to support the idea of voluntarily segregation. If all those people with the desire to leave the neighbourhood were able to effectuate their plans, there would probably be more segregated neighbourhoods. We should keep in mind, however, that the interaction effects are quite small. So, although the effects are significant, they seem to play only a minor part in explaining people's wish to leave the neighbourhood compared with other effects in the model. The simulation results which are presented in the next section will give some more insight in the size of the effects.

The categorization ethnic minorities, as used up to now, refers to a heterogeneous group of people but there may well be substantial differences in the effect of concentrations of different subgroups on moving wishes. We therefore also tested the effect of separate groups according to the country of origin of the parents. In Model 5 the variable percentage of ethnic minorities is split into five separate categories of ethnic minorities. The results show that the percentage of Surinamese in a neighbourhood has no effect at all on moving wishes. This is in line with studies which show that in many respects, such as demographic behaviour and labour market participation, the Surinamese are the most similar of all ethnic minorities to the native Netherlands population. (Dagevos et al., 2003). The ethnic group that has the strongest effect on the probability that people have a wish to leave the neighbourhood are the Antilleans. One possible explanation for this might be that, in contrast with other ethnic groups, the Antilleans consists for a large part of young people who come to the Netherlands alone and settle here without their parents (Dagevos et al., 2003). They often live in nonfamily households without any parental control. Behaviour that other people in the neighbourhood perceive as disturbing may occur among those young Antilleans more often than among other ethnic minorities. A high percentage of Moroccans in the neighbourhood also has a significant impact on moving wishes, but the effect is much smaller than the effect of Antilleans (0.035 versus 0.085). The variance at neighbourhood level in Model 5 is smaller than in Model 4, which indicates that distinguishing the different ethnic groups reflects reality better than treating all ethnic minorities as one category.

There are several possible explanations for the above findings; it is not possible, however, to explore the mechanism in more detail on the basis of the data used in this study. The results must therefore be interpreted with great care. One possible explanation is that the presence of (some members of) the Antillean and Moroccan community causes a nuisance, which makes people want to leave the neighbourhood. Alternatively, the effect might be caused by discrimination of Antilleans and Moroccans by other ethnic minorities and the native Netherlands population. A further possible explanation for the findings is that the presence of Antilleans and Moroccans correlates with unmeasured neighbourhood characteristics that increase the likelihood that people want to leave their neighbourhood (and cause a poor living environment). If this were the case it would not be the presence of certain groups that causes people to want to leave, but rather the neighbourhood in which these concentrations live.

\section{Simulation results}

The results in Table 2 show that the main neighbourhood effects and the interaction effects with the individual characteristics seem to be quite small. To get a better idea of the 
magnitude of these effects on peoples' wish to leave the neighbourhood we simulated these for 'average' respondents. Predicted probabilities were calculated based on the coefficients of Model 4, using average scores for continuous variables and modus scores for categorical variables (see Table 1). Consequently, the predicted outcomes refer to people aged 47, with a partner and children, an average level of education, living in a single-family dwelling, with at least one room per household member, satisfied with their dwelling, and living in a strongly urbanized area. The only variables which were allowed to vary were income, ethnicity, and tenure and the percentages of low incomes, ethnic minorities and renters in the neighbourhood. In the simulations, predicted probabilities are calculated for the whole range from 0 to 100 percent of ethnic minorities in the neighbourhood, while in reality the highest percentage of ethnic minorities in a Netherlands neighbourhood is 85 percent (see Table 1). This maximum is marked in the figure by a vertical dashed line.

Figure 1 shows the predicted probability that ethnic minorities and others want to leave their neighbourhood for different percentages of ethnic minorities in the neighbourhood. The starting point for both curves is about the same, reflecting the fact that there is no significant main effect of individual ethnicity in Model 4. Both curves rise steeply, indicating that both ethnic minorities themselves and others are more likely to wish to leave the neighbourhood with increasing percentages of ethnic minorities in the neighbourhood. The fact that the two curves diverge reflects the significant interaction effect of individual ethnicity and the percentage of ethnic minorities in the neighbourhood. For people not belonging to an ethnic minority, the predicted probability that they want to leave the neighbourhood increases from 0.13 for neighbourhoods without ethnic minorities to around 0.57 for neighbourhoods populated only by ethnic minorities. For people from ethnic minorities themselves, the probability increases from 0.14 to 0.27 , which is still less than half of the probability of the native Netherlands population. Repeating the simulations for others than the 'average' respondent, results in curves that have a higher or lower starting point on the Y-axis, but a shape and relative position similar to the curves for ethnic minorities and non-ethnic minorities in Figure 1. For those with many characteristics that increase the wish to leave the neighbourhood (such as being young, living in rented housing, and being unsatisfied with the dwelling), the estimated probability to have the wish to leave approaches one.

\section{---- please insert Figure 1 about here ----}

Figure 2 shows the predicted probability that renters and homeowners want to leave their neighbourhood for different percentages of rented dwellings in the neighbourhood. The curve for renters starts at a higher point (0.21) than the curve for homeowners $(0.13)$, which reflects the main effect of tenure that renters are more likely to have the wish to leave. An increase in the percentage of rented dwellings in the neighbourhood has a small, but significant, effect on the probability that homeowners want to move (increase to 0.16 ), while the probability that renters want to move decreases to 0.18 for a neighbourhood with 100 percent rented dwellings. Note that the y-axis in Figure 2 is scaled different compared to Figure 1.

\section{---- please insert Figure 2 about here ----}

The simulation results in Figures 1 and 2 confirm the hypothesis that an individual whose characteristics match those of the neighbourhood population is less likely to have the wish to leave the neighbourhood than does an individual whose characteristics differ from those of the neighbourhood population. This finding is most pronounced for the percentage of ethnic minorities in the neighbourhood and less so for the percentage of renters and the percentage 
of low incomes in the neighbourhood. The simulation for the percentage of low incomes in the neighbourhood is not shown, since the main effect is not significant and the interaction effect only very small.

\section{Conclusion}

The results show that with an increasing percentage of ethnic minorities in the neighbourhood, people are more likely to have the wish to leave their neighbourhood. Further, the results lend some support to the hypothesis based on Schelling's work that, when people's own characteristics match the characteristics of the neighbourhood population, they are less likely to want to leave their neighbourhood. This hypothesis was confirmed for all three neighbourhood effects investigated, but the evidence is strongest for ethnicity. Compared to the other variables in the model, including the degree of urbanization variable, the parameters in the models suggest only small effects of the three social characteristics of neighbourhoods on peoples' wish to leave their neighbourhood. However, it has to be taken into account that these social characteristics are measured in percentages (as compared to dummies) and the simulations show that for an 'average' respondent the effects can actually be quite large. Presumably, 'negative' neighbourhood characteristics are perceived as negative to a lesser extent by the neighbourhood residents who have this characteristic themselves. It is not possible to conclude from our data what mechanism lies behind the wish to leave of people who do not match the neighbourhood population. Is it that they do not feel at ease among many people who are different from themselves? Is it that they disapprove of people with different characteristics than their own? Or is it that the presence of (people with) these characteristics stands for other elements in the neighbourhood that are not measured in our data, but which make people want to leave the neighbourhood?

There are several reasons to believe that our results underestimate the real effect of neighbourhood characteristics on people's wish to leave the neighbourhood. First, it can be expected that even by looking at moving wishes we underestimated the category of people who would like to leave their neighbourhood. Not all the people who would like to leave their neighbourhood will say so. Cognitive dissonance reduction might lead people who see few options for leaving the neighbourhood to state that they are happy where they live now. Second, although the simulations clearly show that the scale of the effect of people's own ethnic background is quite large, it may be the case that the simulations understate the true long-run impact. The simulations show the neighbourhood effects at one point in time, but over the longer term the ethnicity share of neighbourhoods is endogenous and changes with more people selectively moving out of the neighbourhood. Because the long-run effect is greater than the one period effect it can be expected that the model will generate increasing returns, suggesting that segregation rises further. Third, the main point of this study is that people select themselves into (or out of) neighbourhoods which fit (or not) their preferences towards neighbourhood characteristics. This same point can be expected to have an effect on the model outcomes because those who are most likely to respond to negative neighbourhood characteristics can be expected not to live in such neighbourhoods in the first place. This clearly is not a perfect selection process as almost 20 percent of the people in our data stated that they would like to leave their neighbourhood. However, the process of self-selection probably leads us to underestimate the effects of neighbourhood characteristics because we only observe people when they already live in a neighbourhood of their choice. To overcome this problem more tailored (longitudinal) datasets are needed which include information on how people sorted into their neighbourhood. Dealing with selection effects in modelling neighbourhood effects is a major challenge for future research.

Although the effects of living in concentration neighbourhoods on moving wishes were found to be relatively small, the results of this study are potentially important in 
understanding segregation. One has to be careful concluding that the findings support the idea of voluntary segregation because a reduction in the likelihood of having a wish to leave is not the same thing as a strong desire to live among one's own kind. However, Schelling has already argued that even small differences in preferences towards the neighbourhood population may result in high levels of segregation in the aggregate.

The outcomes of the research reported in this paper might shed some light on the future success of mixed housing strategies as stated explicitly by governments in the Netherlands, the United Kingdom, Germany, France, Finland, and Sweden (Atkinson \& Kintrea, 2001; Kearns 2002; Musterd et al., 1999). The idea is that mixing tenure and housing types in neighbourhoods creates a more diversified socioeconomic mix, which creates better social opportunities for individuals (Musterd \& Anderson, 2005). In the Netherlands, experiments have been carried out to create more mixed neighbourhood populations. Some of these policies were aimed at mixing in terms of ethnicity (although never stated explicitly), while others have referred to creating socially mixed neighbourhoods based on income. One example is to build owner-occupied houses in neighbourhoods with mainly rented houses. Another example is to give priority status in housing allocation systems to above-average-income couples willing to move to a neighbourhood with a high share of low income households. In our study we found that living in concentration neighbourhoods makes people more likely to have a wish to move. We further found some evidence that people prefer to live in neighbourhoods that consist mainly of people who are like themselves in terms of ethnicity and social position. Creating a social mix in neighbourhoods might work as long as the housing market is very tight, because people are restricted in following their preferences. With about 10 percent of the Netherlands population moving each year and more than two thirds of these movers leaving their neighbourhood, our results suggest that when the housing market relaxes and people are able to follow their preferences, levels of segregation are likely to rise. Mixed housing strategies might therefore only work for as long as people are unable to realize their preferences.

\section{Acknowledgements}

The authors would like to thank Steven Durlauf, Charles Manski and Joop Hox for their literature suggestions and help with the econometric issues arising from our analyses. Further, we would like to thank the editors of Environment and Planning A, and the anonymous referees for their useful comments on an earlier version of this paper. Maarten van Ham also worked on this paper while he was a member of the Urban and Regional research centre Utrecht (URU), Faculty of Geosciences, Utrecht University. Peteke Feijten also worked on this paper while working at the Netherlands Institute for Spatial Research (RPB), The Hague, The Netherlands.

\section{References}

Amérigo M, 2002, "A psychological approach to the study of residential satisfaction", in Residential Environments: Choice, Satisfaction, and Behavior Eds J A Aragonés, G Francescato, T Gärling (Bergin and Garvey, Westport, CT) pp 81-99

Atkinson R, Kintrea K, 2001, "Disentangling area effects: evidence from deprived and nondeprived neighbourhoods" Urban Studies 38 2277-2298

Bolt G, Hooimeijer P, Van Kempen R, 2002, “Ethnic segregation in the Netherlands: new patterns, new policies?" Tijdschrift voor Economische en Sociale Geografie 93 214-220

Bolt G, Van Kempen R, 2003, "Escaping poverty neighborhoods in the Netherlands" Housing, theory and society 20 209-222 
Bootsma H G, 1998, The Myth of Reurbanization. Location dynamics of households in the Netherlands (Thela Thesis, Amsterdam)

Brock W A, Durlauf S N, 2005, "A Multinomial Choice Model with Social Interactions" in The Economy as an Evolving Complex System III Eds L Blume, S N Durlauf (Oxford University Press) 175-206

Brock W A, Durlauf S N, 2004, "Identification of Binary Choice Models with Social Interactions", Working paper, Department of Economics, University of Wisconsin.

Brower S, 1996, Good Neighbourhoods: A Study of In-town and Suburban Residential Environments (Praeger, Westport, CT)

Brown L A, Moore E G, 1970, "The intra-urban migration process: a perspective" Geografiska Annaler Series B 52 1-13

Browne W J, 2003, MCMC Estimation in MLwiN (Centre of Multilevel Modelling, Institute of Education, University of London)

Brun J, Fagnani J, 1994, "Lifestyles and locational choices - trade-offs and compromises: a case-study of middle-class couples living in the Ile-de-France region" Urban Studies 31 921-934

Buck N, 2001, "Identifying neighbourhood effects on social exclusion" Urban Studies 38 2251-2275

Clark W A V, 1991, "Residential Preferences And Neighborhood Racial Segregation - A Test Of The Schelling Segregation Model" Demography 28 1-19

Clark W A V, 1992, "Residential Preferences And Residential Choices In A Multiethnic Context" Demography 29 451-466

Clark W A V, Dieleman F M, 1996, Households and Housing. Choice and Outcomes in the Housing Market (Center for Urban Policy Research, New Brunswick, NJ)

Clark W A V, Deurloo M C, Dieleman F M, 2006, "Residential mobility and neighbourhood outcomes" Housing Studies 21 323-342

Coulson N E, Hwang S, Imai S, 2003, "The value of owner occupation in neighbourhoods" Journal of Housing Research 13 153-174

Crowder K, 2000, "The racial context of white mobility: An individual-level assessment of the white flight hypothesis" Social Science Research 29 223-257

Dagevos J, Gijsberts M, Van Praag C, 2003, Rapportage minderheden 2003: Onderwijs, arbeid en sociaal-culturele integratie (Sociaal en Cultureel Planbureau, Den Haag)

Duncan G, Brooks-Gunn J, Klebanov P, 1994, "Economic deprivation and early childhood development" Child Development 65 296-318

Durlauf S N, 2004, "Neighbourhood Effects" in Handbook of Regional and Urban Economics. Volume 4 Cities and Geography Eds J V Henderson, J F Thisse (Elsevier, Amsterdam) 2173-2242

Ellen I G, Turner M, 1997, "Does neighbourhood matter? Assessing recent evidence" Housing Policy Debate 8 833-866

Evans W, Oates W, Schwab R, 1992, "Measuring peer group effects: A study of teenage behaviour" Journal of Political Economy 100 966-991

Feijten P, Mulder C H, Baizan P, 2003, "Age differentiation in the effect of household situation on first-time homeownership" Journal of Housing and the Built Environment 18 233-255

Friedrichs J, Blasius J, 2003, "Social norms in distressed neighbourhoods: Testing the Wilson hypothesis" Housing Studies 18 807-826

Galster G, 2001, "On the nature of neighbourhood" Urban Studies 38 2111-2124

Galster G, 2002, "Trans-Atlantic perspectives on opportunity, deprivation and the housing nexus" Housing Studies 17 5-12 
Galster G, 2003, "Investigating behavioural impacts of poor neighbourhoods: Towards new data and analytic strategies" Housing Studies 18 893-914

Helderman A, Mulder C H, Van Ham M, 2004, "The changing effect of home ownership on residential mobility in the Netherlands, 1980-98" Housing Studies 19 601-616

Ihlanfeldt K R, Scafidi B, 2002, "Black self-segregation as a cause of housing segregation: Evidence from the multi-city study of urban inequality" Journal of Urban Economics $\mathbf{5 1}$ 366-390

Ioannides Y M, Zabel J E, 2003, "Neighbourhood effects and housing demand" Journal of Applied Econometrics 18 563-584

Kearns A, 2002, "Response: from residential disafvantage to opportunity? Reflections on British and European policy and research" Housing Studies 17 145-150

Kearns A, Parkes A, 2003, "Living in and leaving poor neighbourhood conditions in England" Housing Studies 18 827-851

Lansdale N S, Guest A M, 1985, "Constraints, satisfaction and residential mobility: Speare's model reconsidered" Demography 22 199-222

Leventhal T, Brooks-Gunn J, 2000, "The neighbourhoods they live in: the effects of neighbourhood residence on child and adolescent outcomes" Psychological Bulletin 126 309-337

$\mathrm{Lu} \mathrm{M}, 1999$, "Do people move when they say they will? Inconsistencies in individual migration behaviour" Population and Environment: A Journal of Interdisciplinary Studies 20 467-488

Manski C, 1993, "Identification of endogenous social effects: The reflection problem" Review of Economic Studies 60 531-542

Massey D S, Gross A B, Shibuya K, 1994, "Migration, segregation, and the geographic concentration of poverty" American Sociological Review 59 425-445

McDowell L, 1997, "The new service class: housing, consumption, and lifestyle among London bankers in the 1990s" Environment and Planning A 29 2061-2078

Meen D, Meen G, 2003, "Social behaviour as a basis for modelling the urban housing market: a review" Urban Studies 40 917-935

Moffitt R, 1998, "Policy interventions, low-level equilibria, and social interactions" Johns Hopkins University, Department of Economics, Economics Working Paper Series number 432

Morris E W, Crull S R, Winter W, 1976, "Housing norms, housing satisfaction and the propensity to move" Journal of marriage and the family 38 309-320

Mulder C H, 1993, Migration dynamics: a life course approach (Thesis Publishers, Amsterdam)

Musterd S, Priemus H, Van Kempen R, 1999, "Towards undivided cities: the potential of economic revitalisation and housing differentiation" Housing Studies 14 573-584

Musterd S, Ostendorf W, de Vos S, 2003, "Neighbourhood effects and social mobility: A longitudinal analysis" Housing Studies 18 877-892

Musterd S, Anderson R, 2005, "Housing mix, social mix, and social opportunities" Urban Affairs Review 40 761-790

Overman H G, 2002, "Neighbourhood effects in large and small neighbourhoods" Urban Studies 39 117-130

Parkes A, Kearns A, Atkinson R, 2002, "What makes people dissatisfied with their neighbourhoods?" Urban Studies 39 2413-2438

Plotnick R, Hoffman S, 1999, "The effect of neighborhood charateristics on young adult outcomes: Alternative estimates" Social Science Quarterly 80 1-18

Rasbash J, Steele F, Browne W, Prosser B, 2004, A user's guide to MLwiN version 2.0 (Institute of Education, London) 
Rossi P H, 1955, Why families move. A study in the social psychology of urban residential mobility (Free Press, Glencoe, Illinois)

Sampson R, Morenoff J, Gannon-Rowley T, 2002, “Assesing 'neighborhood effects': Social processes and new directions in research" Annual Review of Sociology 28 443-478

Schelling T C, 1969, "Models of segregation" The American Economic Review 59 488-493

Schelling T C, 1971, "Dynamic models of segregation" Journal of mathematical sociology 1 143-186

Snijders T A B, Bosker R J, 1999, Multilevel analysis: An introduction to basic and advanced multilevel modeling (Sage, London)

South S J, Crowder K D, 1997, "Residential mobility between cities and suburbs: race, suburbanization, and back-to-the-city moves" Demography 34 525-538

Speare A, Goldstein S, Frey W H, 1975, Residential mobility, migration, and metropolitan change (Ballinger, Cambridge Mass.)

Spiegelhalter D J, Best N G, Carlin B P, van der Line A, 2002, "Bayesian measures of model complexity and fit" Journal of the Royal Statistical Society Series B 64 583-640

Talen E, 2001, "Traditional urbanism meets residential affluence: an analysis of the variability of suburban preference" Journal of the American Planning Association 67 199-216

Van der Klaauw B, Van Ours J C, 2003, "From welfare to work: does the neighborhood matter?" Journal Of Public Economics 87 957-985

Varady D P, 1989, "The impact of city/suburban location on moving plans: a Cincinnati study" Growth and Change 20 35-49.

Wilson W, 1987, The truly disadvantaged. The inner city, the underclass and public policy (University of Chicago Press, Chicago) 
Table 1. Variable summary statistics $(\mathrm{N}=62,144)$

\begin{tabular}{|c|c|c|c|c|}
\hline Variable name & Categories & $\mathbf{N}(\%)$ & Min./max. & Mean (s.d.) \\
\hline \multicolumn{5}{|c|}{ Personal and household characteristics } \\
\hline \multirow{2}{*}{$\begin{array}{l}\text { Wish to leave the neighbourhood } \\
\text { (dependent variable) }\end{array}$} & No wish & $50,510(81.3)$ & & \\
\hline & wish & $11,634(18.7)$ & & \\
\hline Age & & & $18-80$ & $46.7(15.4)$ \\
\hline Age squared / mean age & & & $6.95-137.28$ & $51.8(33.0)$ \\
\hline \multirow[t]{5}{*}{ Household composition } & One-person household & $15,411(24.8)$ & & \\
\hline & Couple & $20,831(33.5)$ & & \\
\hline & Couple with children & $20,893(33.6)$ & & \\
\hline & One-parent household & $3,406(5.5)$ & & \\
\hline & Other $^{\mathrm{a}}$ & $1,603(2.6)$ & & \\
\hline Disposable yearly income (/€1000) & & & $0-543.9$ & $29.0(19.1)$ \\
\hline \multirow{2}{*}{$\begin{array}{l}\text { Income }=\text { low (income-dummy } \\
\text { needed for interaction-effect) }\end{array}$} & Yes, income is low & $11,130(17.9)$ & & \\
\hline & No, income is not low & $51,014(82.1)$ & & \\
\hline \multirow[t]{3}{*}{ Educational level $^{\mathrm{c}}$} & Low & $17,901(28.8)$ & & \\
\hline & Middle & $27,900(44.9)$ & & \\
\hline & High & $16,343(26.3)$ & & \\
\hline \multirow[t]{2}{*}{ Ethnicity $^{\mathrm{d}}$} & $\begin{array}{l}\text { Belonging to ethnic } \\
\text { minority }\end{array}$ & $5,021(8.1)$ & & \\
\hline & $\begin{array}{l}\text { Not belonging to ethnic } \\
\text { minority }\end{array}$ & $57,123(91.9)$ & & \\
\hline \multicolumn{5}{|l|}{ Dwelling characteristics } \\
\hline \multirow[t]{2}{*}{ Tenure } & Owner-occupied & $35,283(56.8)$ & & \\
\hline & Rented & $26,861(43.2)$ & & \\
\hline \multirow[t]{2}{*}{ Type of dwelling } & Flat/apartment & $17,692(28.5)$ & & \\
\hline & Single-family dwelling & $44,452(71.5)$ & & \\
\hline \multirow[t]{2}{*}{ Housing satisfaction $^{\mathrm{e}}$} & Satisfied & $55,475(89.3)$ & & \\
\hline & Neutral or unsatisfied & $6,669(10.7)$ & & \\
\hline \multirow[t]{2}{*}{ Numer of rooms per hh member } & Less than one room & $2,023(3,3)$ & & \\
\hline & One room or more & $60,121(96.7)$ & & \\
\hline \multicolumn{5}{|l|}{ Neighbourhood characteristics } \\
\hline Percentage of low incomes & & & $0-63.8$ & $19.5(8.4)$ \\
\hline Percentage of high incomes & & & $0-84.5$ & $20.1(8.4)$ \\
\hline Percentage of ethnic minorities & & & $0-85.0$ & $10.0(12.0)$ \\
\hline Percentage of Surinamese & & & $0-39.3$ & $2.0(3.6)$ \\
\hline Percentage of Antillians & & & $0-10.4$ & $0.8(1.1)$ \\
\hline Percentage of Turks & & & $0-33.4$ & $2.2(3.9)$ \\
\hline Percentage of Morrocans & & & $0-37.3$ & $2.0(3.5)$ \\
\hline $\begin{array}{l}\text { Percentage of other non-Western } \\
\text { ethnic minorities }\end{array}$ & & & $0-51.5$ & $3.1(3.0)$ \\
\hline Percentage of rented dwellings & & & $0-100$ & $45.3(18.7)$ \\
\hline \multirow[t]{5}{*}{ Degree of urbanization ${ }^{\mathrm{f}}$} & Not urbanized & $9,345(15.0)$ & & \\
\hline & Weakly urbanized & $11,385(18.3)$ & & \\
\hline & Urbanized & $13,308(21.4)$ & & \\
\hline & Strongly urbanized & $15,874(25.5)$ & & \\
\hline & Very strongly urbanized & $12,232(19.7)$ & & \\
\hline
\end{tabular}

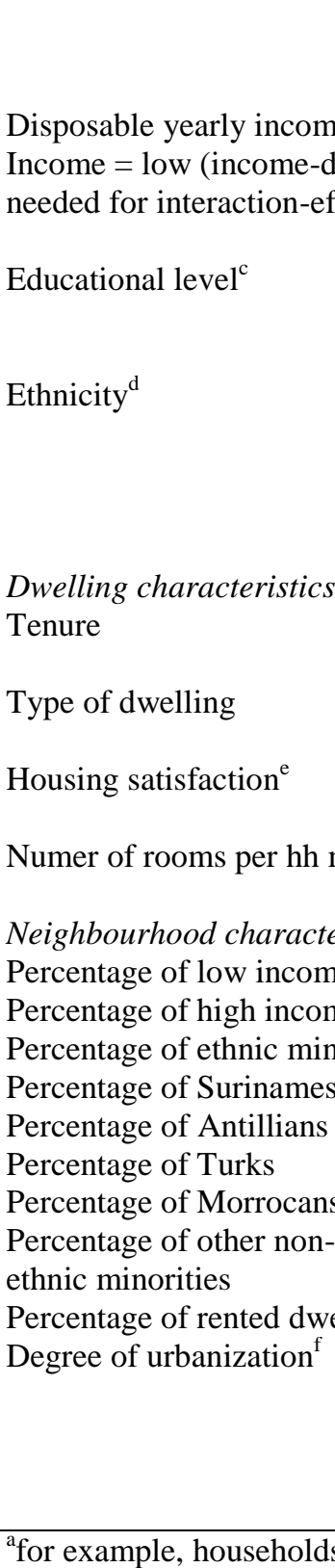

for example, households with cohabiting grandparents

bdefined as an income on or below the official minimum wage level

'defined as the respondent's highest completed level of education (low = primary education + lower vocational training; middle $=$ secondary education/high school, middle vocational training; high $=$ higher vocational training + university) detnic minorities are defined as people with at least one parent born in Africa (of these, Moroccans are the largest group), Asia (excluding Japan and Indonesia, which belonged to the Netherlands Kingdom until 1949); Latin America; Turkey; Surinam or the Netherlands Antilles

ederived by reducing a five-point satisfaction scale into a dichotomous satisfied/neutral-or-unsatisfied variable f based on the average density of addresses per square kilometre in the postcode area (not urbanized < 500; weakly urbanized $=500-1,000 ;$ urbanized $=1,000-1,500 ;$ strongly urbanized $=1,500-2,500 ;$ very strongly urbanized $>2,500$ ) 
TABLE 2. Multilevel logistic regression ${ }^{1}$ of the wish to leave the neighbourhood $(\mathrm{N}=62,144)$

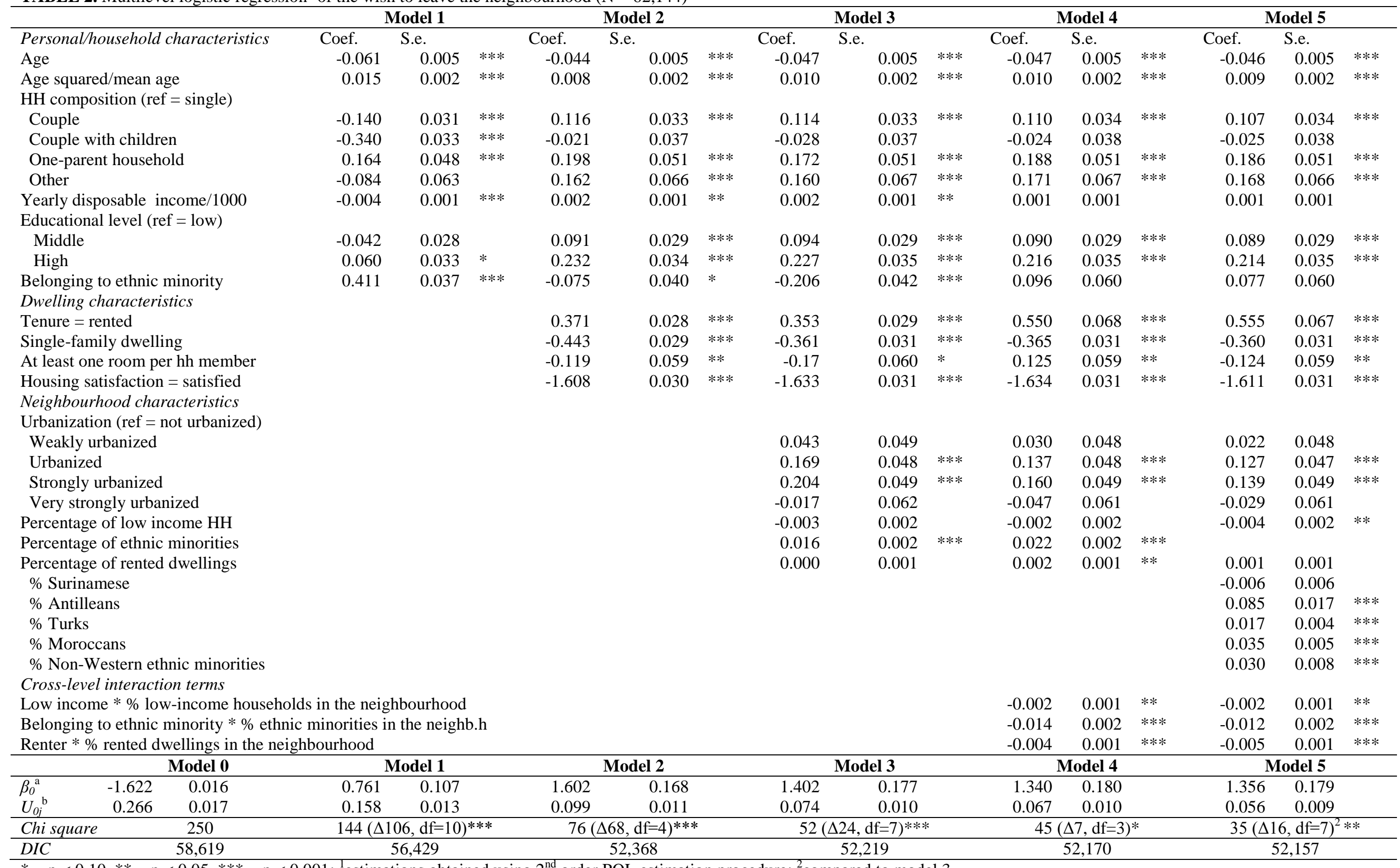

$*=\mathrm{p}<0.10, * *=\mathrm{p}<0.05, * * *=\mathrm{p}<0.001 ;{ }^{1}$ estimations obtained using $2^{\text {nd }}$ order PQL estimation procedure; ${ }^{2}$ compared to model 3 
FIGURE 1. Estimated probability to have a moving wish by ethnic background; by percentage of people from ethnic minorities in the neighbourhood

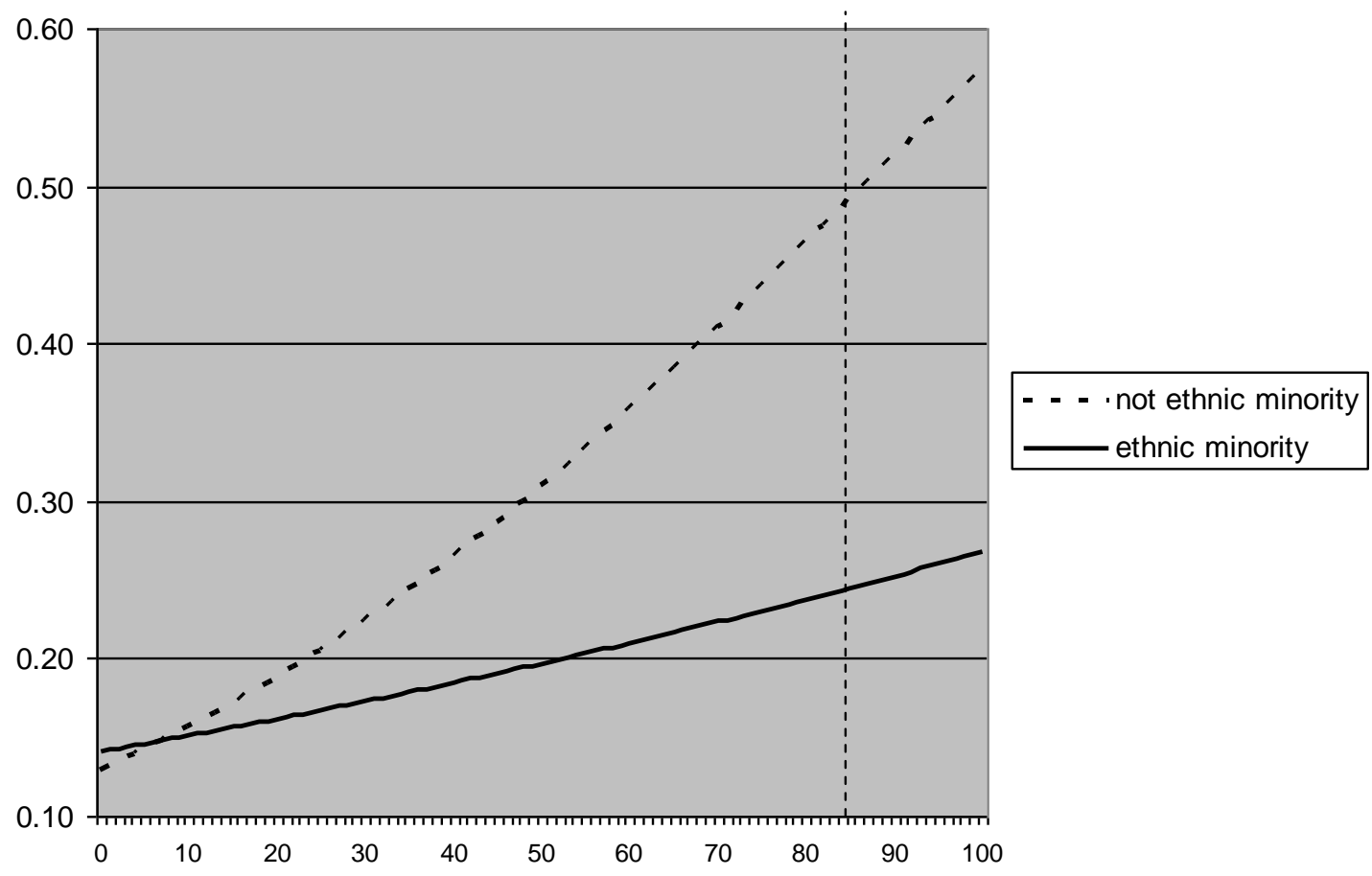

FIGURE 2. Estimated probability to have a moving wish for renters and homeowners; by percentage of rental dwellings in the neighbourhood

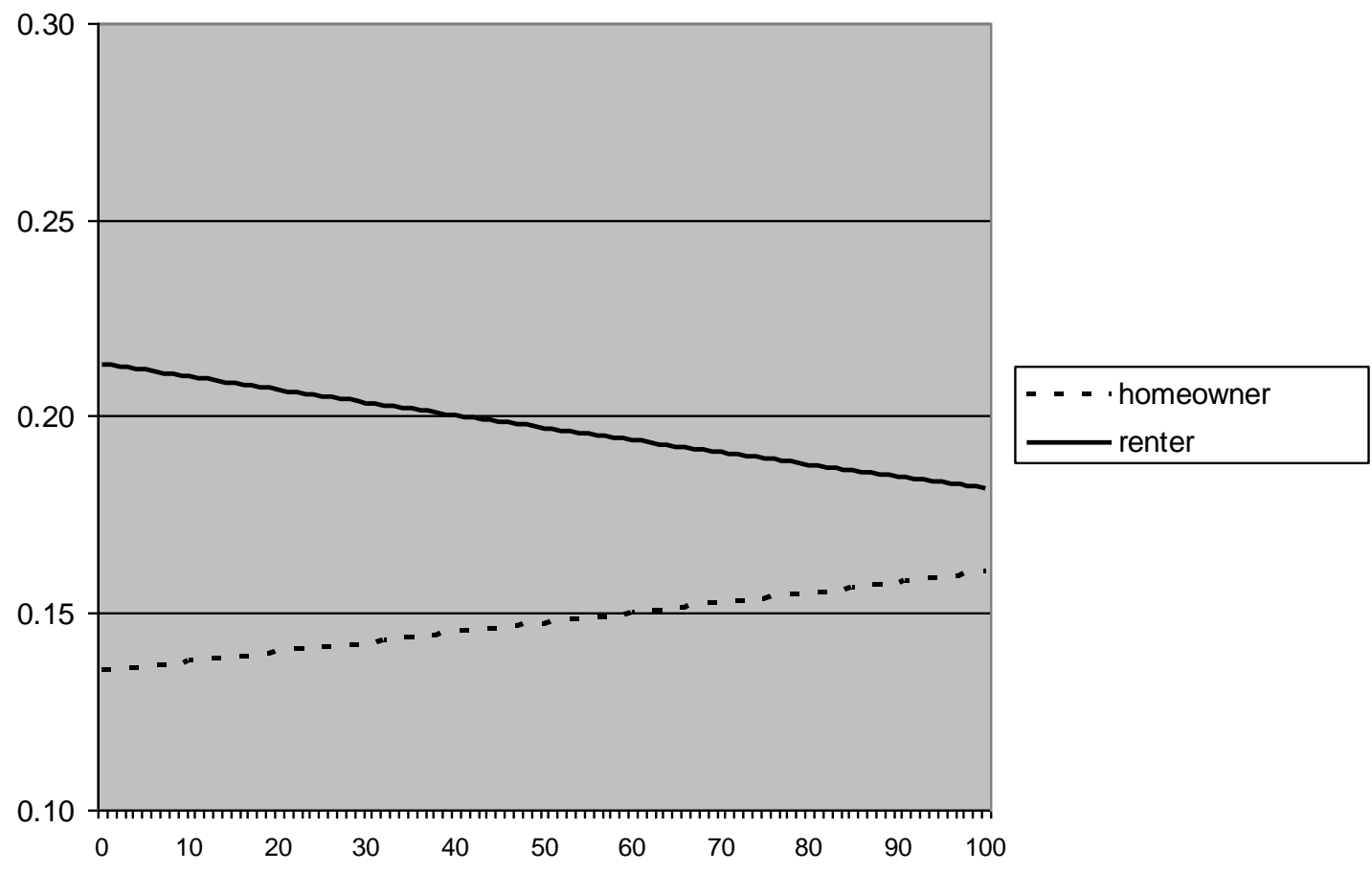

